\title{
BRIÓFITAS EPÍXILAS DE UMA ÁREA REMANESCENTE DE FLORESTA ATLÂNTICA (TIMBAÚBA, PE, BRASIL). 2. LEJEUNEACEAE
}

\author{
Shirley Rangel Germano ${ }_{2}$ \\ Kátia Cavalcanti Pôrto ${ }^{2}$
}

Recebido em 23/9/97. Aceito em 5/3/98

\begin{abstract}
RESUMO - (Briófitas epíxilas de uma área remanescente de Floresta Atlântica (Tímbaúba, PE, Brasil) 2. Lejeuneaceae). Foram registradas 19 espécies de Lejeuneaceae epixilas em um remanescente de Floresta Tropical Atlântica no municipio de Timbaúba ( $\left.7^{\circ} 35^{\prime} \mathrm{S}, 35^{\circ} 20^{\prime} \mathrm{W}\right)$, Estado de Pernambuco. Constituem novas referências para a região Nordeste - Aphanolejeunea sicaefolia (Gott. in Steph.) Evans e Cheilolejeunea trifaria (Reinw. et al.) Mizut. Há indicação de bibliografia referentes à descrição, ilustração e distribuição geográfica no Brasil, além de chave de identificação para os táxons encontrados.

Palavras-chave: briófitas, hepáticas, Lejeuneaceae, epíxila

ABSTRACT - (Epixylic Bryophytes of an remnant area of the Atlantic Forest (Timbaúba, PE, Brazil). 2. Lejeuneaceae). A survey of epixylic bryoflora of a remaining Atlantic Forest, in the municipality of Timbaúba $\left(7^{\circ} 35^{\circ} \mathrm{S}, 35^{\circ} 20^{\circ} \mathrm{W}\right)$, State of Pernambuco, registered 19 species of the Lejeuneaceae family. New records for Northeast of Brazil are: Aphanolejeunea sicaefolia (Gott. in Steph.) Evans and Cheilolejeunea trifaria (Reinw. et al.) Mizut. There are an indication of the description, illustration, geographic distribution for Brazil and identification key for genera and species.
\end{abstract}

Key words: bryophytes, liverworts, Lejeuneaceae, epixylic

\section{Introdução}

Lejeuneaceae é a maior família das hepáticas, estando representada no Novo Mundo por várias centenas de espécies e cerca de 70 gêneros (Gradstein 1994).

O primeiro e o mais extenso trabalho a respeito da família no Brasil foi o de Spruce (1884), que tratou das hepáticas da região Amazônica. Nesta obra, foram descritos vários subgêneros, muitos dos quais atualmente elevados à categoria de gênero. Entre as publicações mais recentes destacam-se a de Baptista (1977), que realizou levantamento para o Rio Grande do Sul, incluindo revisão bibliográfica para

\footnotetext{
Bolsista DCR (CNPq) - UFPE

Departamento de Botânica, Universidade Federal de Pernambuco, Av. Nelson Chaves s/n, CEP 50760-420

Recife, PE
} 
o Brasil, chaves de identificação, descrições e ilustrações dos gêneros, e a de Giancotti \& Vital (1989) que fizeram inventário da Reserva Biológica do Alto da Serra de Paranapiacaba, SP, relacionando 14 gêneros e 20 espécies. Estes últimos autores, através do exame da coleção do Herbário do Estado "Maria Eneyda P. Kauffmann Fidalgo", do Instituto de Botânica (SP) e de citações bibliográficas referentes ao período de 1920-1960, verificaram decréscimo no número de táxons, anteriormente de 25 gêneros e 66 espécies, e atribuíram o fato à elevada poluição emanada pelo pólo industrial de Cubatão.

Representantes de Lejeuneaceae habitam diversos tipos de formações vegetais e variados substratos, destacando-se nas florestas tropicais, em grau de importância, os troncos vivos seguidos por troncos mortos, como os mais favoráveis ao estabelecimento das briófitas (Pócs 1982; Richards 1984).

O inventário florístico das briófitas de uma área de floresta tropical do Estado de Pernambuco colonizadoras de troncos mortos, em diferentes estádios de decomposição, indicou ser Lejeuneaceae a família de maior riqueza genérica e específica (Germano \& Pôrto 1996), bem como, que a maioria das espécies da família não apresentou especificidade em relação ao fator decomposição (Germano \& Pôrto 1997). Dada a sua importância, Lejeuneaceae mereceu neste trabalho um estudo mais detalhado, o qual complementa o levantamento florístico das briófitas epíxilas iniciado por Germano \& Pôrto (1996).

\section{Material e métodos}

A mata do Engenho Água Azul está situada no município de Timbaúba, PE e encontra-se descrita em Germano \& Pôrto (1996). O trabalho de campo foi realizado durante 12 meses, em excursões bimestrais.

Para coleta e herborização do material seguiu-se a técnica indicada por Yano (1984a). Coletaram-se briófitas em um total de 54 troncos caídos e mortos, selecionados de acordo com o perímetro $(50>75 \mathrm{~cm})$ e o grau de decomposição (reduzida, intermediária e avançada), segundo a metodologia de McCullough, de 1948, modificada (apud Söderström 1987), a qual é descrita detalhadamente em Germano \& Pôrto (1997).

A identificação das amostras foi baseada na literatura especializada. As exsicatas encontram-se depositadas no Herbário da Universidade Federal de Pernambuco (UFP).

São apresentadas: chave analítica de identificação; indicação de bibliografia, que contém descrição e ilustração detalhadas de cada táxon, exceto aqueles citados pela primeira vez para a região Nordeste; distribuição geográfica no Brasil (utilizandose as siglas oficiais dos Estados), com base nos trabalhos de Yano (1984b; 1989; 1995), Yano \& Lisboa (1988), Pôrto (1990), Schäfer-Verwimp \& Vital (1989), SchäferVerwimp (1991), Vital et al. (1991), Yano \& Mello (1992), Vital \& Visnadi (1994).

\section{Resultados}

A flora de Lejeuneaceae epíxila da floresta estudada é composta por 14 gêneros e 19 espécies, das quais duas são novas referências para a região Nordeste: 
Aphanolejeunea sicaefolia (Gott. in Steph.) Evans e Cheilolejeunea trifaria (Reinw. et al.) Mizut.

Chave de identificação para os táxons encontrados

1. Gametófitos pequenos, menores que $1 \mathrm{~mm}$ larg, anfigastros ausentes . (COLOLEJEUNEOIDEAE) 1. Aphanolejeunea sicaefolia

1. Gametófitos pequenos ou grandes, maiores que $1 \mathrm{~mm}$ larg., anfigastros presentes

2. Gametófitos verde-escuros ou marrons até pretos, anfigastros inteiros, merófito ventral com numerosas células, mais de 10 fileiras de células .....

PTYCHANTHOIDEAE (3)

2. Gametófitos verde-claros a amarelados, às vezes brilhantes e transparentes, raramente marrons, anfigastros em geral bífidos, merófito ventral usualmente 4 , até 5-7 fileiras de células LEJEUNEOIDEAE (6)

3. Ocelos numerosos, inclusive no anfigastro e no perianto; células da margem do filídio retangulares e hialinas, em 2-3 fileiras ........ 18. Stictolejeunea squamata

3. Ocelos ausentes; células da margem de várias formas, não hialinas .................... 4

4. Células do filídio de pigmentação escura, quilhas do perianto laciniadas ou denteadas

4. Células do filídio sem pigmentação escura, perianto de quilhas lisas ou debilmente denticuladas

16. Archilejeunea fuscescens

5. Perianto lateral em ramo curto, inovação curta; linha de inserção do anfigastro profundamente arqueada

19. Symbiezidium barbiflorum

5. Perianto terminal no caulídio ou no ramo longo, inovações ausentes; linha de inserção do anfigastro pouco arqueada ou reta ....... 17. Lopholejeunea subfusca

6. Filídios com ocelos .................................................................................. 7

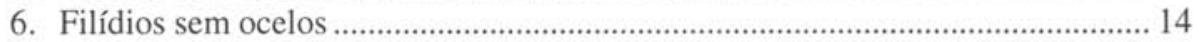

7. Anfigastro de lobos obtusos ................................................... Harpalejeunea (8)

7. Anfigastro de lobos agudos ............................................................................ 9

8. Ápice do filídio agudo a acuminado; margem inteira a ondulada

8. Ápice do filídio com 2 dentes pluricelulares; margem crenulada

9. H. tenuicuspis

8. Harpalejeunea sp.

9. Gametófitos marrom-avermelhados até pretos, lustrosos

Ceratolejeunea (10)

9. Gametófitos verde-claros, raramente verde-escuros, opacos ............................. 11

10. Anfigastros pequenos, 2-3 vezes o caulídio, orbiculares; lóbulo amplamente ovalado, inflado, dente apical longo e curvo

2. C. cubensis

10. Anfigastros mais largos que longos, 4-6 vezes o caulídio, ovalados a amplamente reniformes; lóbulo pequeno, em geral esférico, dente apical curto

3. C. maritima

11. Gametófitos pequenos, verde-claros a amarelados, filídios distantes, assimétricos, estreitos, 3-4 células larg., 3 ocelos, medianos, em série..... 
11. Gametófitos robustos, verdes, às vezes tornando-se marrons com a idade, filídios simétricos, mais de 4 células larg., 3 ou mais ocelos, basais 12

12. Ocelos 4-8, anfigastros grandes, 5-8 vezes o caulídio, inovações 1-2 13. Pycnolejeunea contigua

12. Ocelos 3-5, anfigastros pequenos, 2-4 vezes o caulídio, inovações ausentes .... 13

13. Margem do filídio inteira ou ligeiramente crenulada, trigônios ausentes, ramos flageliformes freqüentes, filídios com rizóides marginais

14. Rectolejeunea flagelliformis

13. Margem do filídio denticulada, trigônios pequenos, ramos flageliformes e rizóides marginais ausentes

15. Trachylejeunea crenata

14. Margem do filídio fortemente crenulada, quilhas do perianto laciniadas

12. Prionolejeunea luensis

14. Margem do filídio inteira, quilhas do perianto lisas ou pouco crenuladas ........ 15

15. Filídios imbricados, trigônios e oleocorpos grandes, estes em número reduzido, papila hialina distal

Cheilolejeunea (16)

15. Filídios distanciados a subimbricados; trigônios e oleocorpos pequenos, estes numerosos, papila hialina proximal

Lejeunea spp.

16. Filídios caducos freqüentes; rizóides marginais presentes, espessamentos intermédios 2-3

4. C. adnata

16. Filídios perenes; rizóides marginais e espessamentos intermédios ausentes ... 17

17. Oleocorpos 1-2 por célula; anfigastros orbiculares a reniformes, $3-5$ vezes o caulídio, inserção profundamente arqueada

6. C. trifaria

17. Oleocorpos 3-4 por célula; anfigastros levemente ovalados, 2-3 vezes o caulídio, inserção reta ou quase

5. C. rigidula

LEJEUNEACEAE

COLOLEJEUNEOIDEAE

1. Aphanolejeunea sicaefolia (Gott. in Steph.) Evans, Bull. Torrey Bot. Club. 38: 277. 1911. (Fig. 1-4)

Descrição: Evans (1911).

Material examinado: BRASIL. Pernambuco: Timbaúba, mata do Engenho Água Azul, 17/VII/92, tronco morto, Germano s/n (UFP 8679a); 11/IX/92, tronco morto, Pôrto s/n (UFP 9238); 9/II/93, tronco morto, Germano s/n (UFP 8720).

Distribuição no Brasil: PE, SP.

Comentários: Ocorre sobre troncos nas três fases de decomposição, em geral associada a outras hepáticas. Espécie frágil, de difícil visualização no campo, devido ao seu tamanho reduzido. Apresenta como características principais: 2 tipos de filídios em um só ramo, os maiores lanceolados, com lóbulos bem desenvolvidos e os menores, com lóbulos rudimentares ou ausentes; filídio de ápice estreitamente acuminado, margem crenulada por projeção das células e lóbulo com dente apical unicelular, longo, curvo e papila hialina distal. 

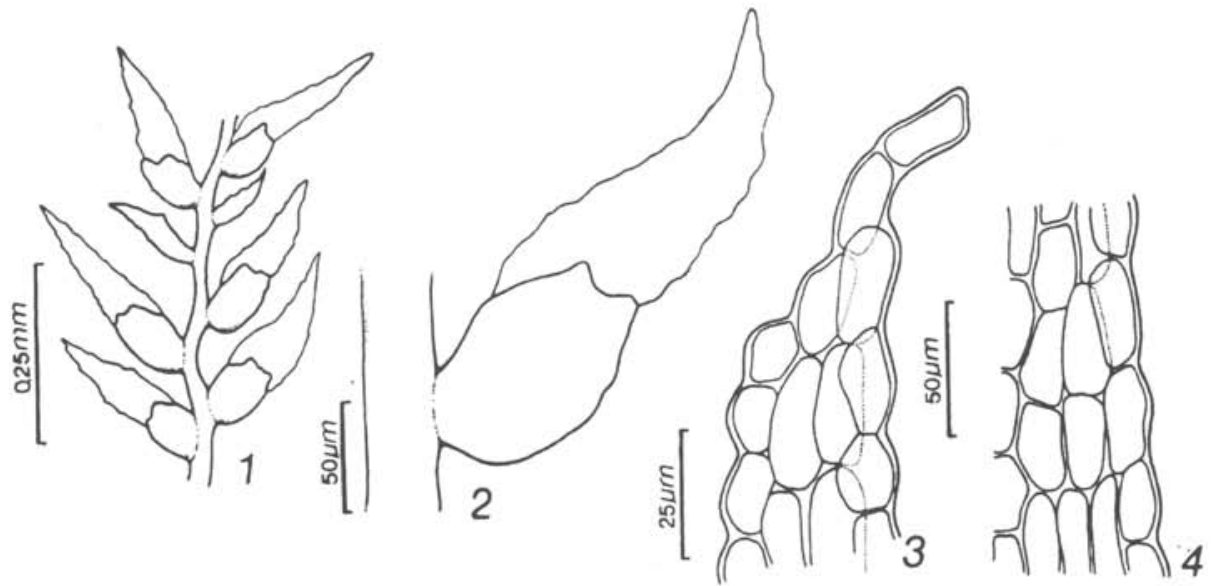

Figuras 1-4. Aphanolejeunea sicaefolia (Gott. in Steph.) Evans. 1. aspecto geral do gametófito. 2.detalhe do filídio com lóbulo. 3. células do ápice. 4. células marginais do filídio.

\section{LEJEUNEOIDEAE}

2. Ceratolejeunea cubensis (Mont.) Schiffn, in Engler \& Prantl, Natür. Pflanzenfam 3: 125.1893.

Descrição e ilustração: Fulford (1945).

Material examinado: BRASIL. Pernambuco: Timbaúba, mata do Engenho Água Azul, 17/VII/92, tronco morto, Germano s/n (UFP 8672); 11/IX/92, tronco morto, Pôrto s/n (UFP 8691a); 9/II/93, tronco morto, Germano s/n (UFP 8712).

Distribuição no Brasil: AC, AM, PA, PE, SP.

Comentários: Ocorre sobre troncos nas três fases de decomposição. Apresenta como características principais: filídios esparsamente denteados no ápice, ocelos 2-3 grandes, basais; lóbulos ovalados, inflados, dente apical longo e curvo; anfigastros orbiculares, pequenos, 2-3 vezes a largura do caulídio.

3. Ceratolejeunea maritima (Spruce) Steph., Spec. Hep. 5: 423. 1913.

Descrição e ilustração: Fulford (1945).

Material examinado: BRASIL. Pernambuco: Timbaúba, mata do Engenho Água Azul, 9/II/93, tronco morto, Germano s/n (UFP 8719a).

Distribuição no Brasil: AM, PA, PE. 
Comentários: Ocorre apenas sobre troncos em decomposição avançada. Espécie de grande polimorfismo, apresentando como características principais: ocelos 2-3 basais; lóbulos ovalados, inflados, dente apical curto; anfigastros largos, ovalados a amplamente reniformes, $3,0-4,5$ vezes a largura do caulídio.

4. Cheilolejeunea adnata (Kunze) Grolle, J. Bryol. 9: 529. 1977.

Descrição e ilustração: Schuster (1980).

Material examinado: BRASIL. Pernambuco: Timbaúba, mata do Engenho Água Azul, 17/VII/92, tronco morto, Germano s/n (UFP 8684a); 11/IX/92, tronco morto, Germano s/n (UFP 8699).

Distribuição no Brasil: AM, MG, PE, PR.

Comentários: Ocorre sobre troncos em decomposição reduzida e intermediária. Apresenta como principais características: trigônios pequenos, espessamentos intermédios 2-3, oleocorpos grandes, 2-4(5), quase que preenchendo o lúmen celular, ocasionalmente podem ser encontrados 1-4 oleocorpos pequenos, em adição aos normais (Schuster 1980); lóbulos ovóides, fortemente inflados, dente apical longo e curvo; anfigastros pequenos, ca. 1,5-2,0 vezes a largura do caulídio. É freqüente a reprodução assexuada por meio de filídios caducos, que portam rizóides marginais.

5. Cheilolejeunea rigidula Schust., Castanea 36: 102. 1971.

Descrição e ilustração: Schuster (1980).

Material examinado: BRASIL. Pernambuco: Timbaúba, mata do Engenho Água Azul, 17/VII/92, tronco morto, Germano s/n (UFP 8676); 9/II/93, tronco morto, Germano s/n (UFP 8703).

Distribuição no Brasil: AC, ES, PE.

Comentários: Ocorre sobre troncos em decomposição reduzida e avançada. Espécie de grande polimorfismo, apresentando como características principais: trigônios grandes, cordados, espessamentos intermédios ausentes, 3-4 oleocorpos por célula; lóbulos pequenos, ovalado-triangulares, com dente apical curto; anfigastros 2,0-3,5 vezes a largura do caulídio.

6. Cheilolejeunea trifaria (Reinw. et al.) Mizut., J. Hattori Bot. Lab. 27: 132. 1964. (Fig. 5-8).

Descrição: Mizutani (1982).

Material examinado: BRASIL. Pernambuco: Timbaúba, mata do Engenho Água Azul, 11/IX/92, tronco morto, Germano s/n (UFP 8692); 9/II/93, tronco morto, Germano s/n (UFP 8718).

Distribuição no Brasil: AC, ES, MG, PR, RR, PE, SP. 


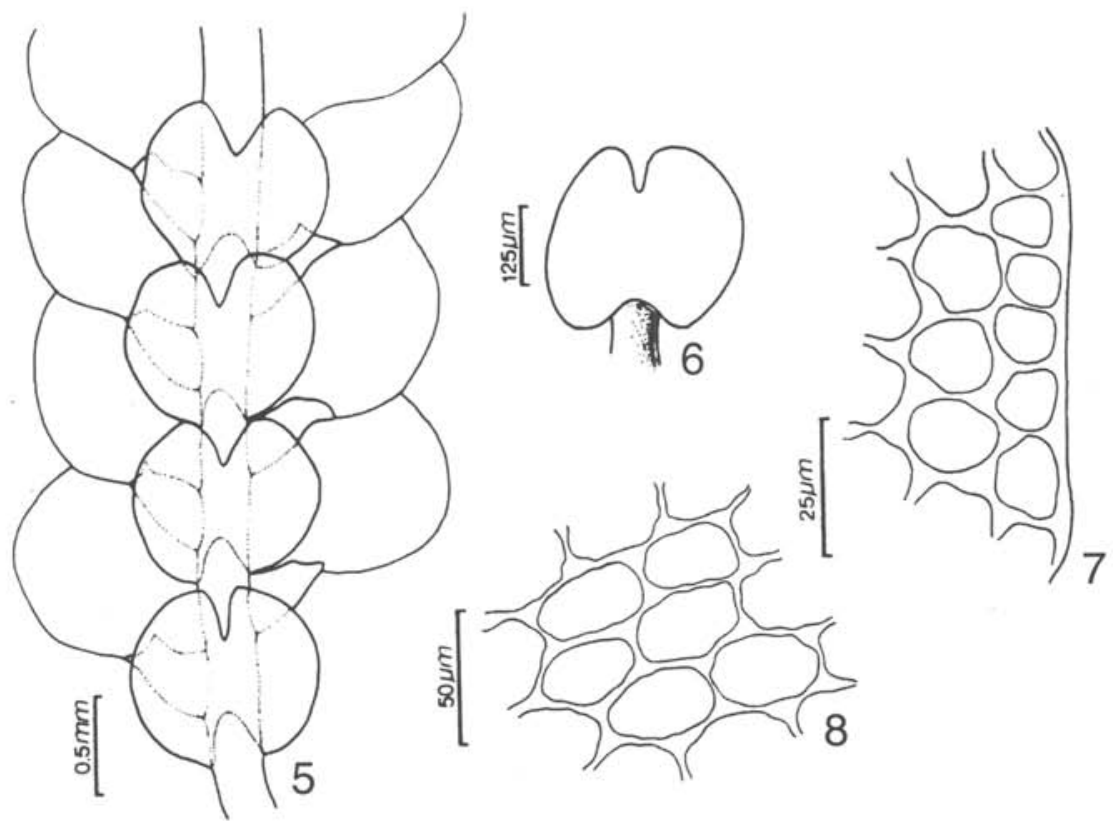

Figuras 5-8. Cheilolejeunea trifaria (Reinw. et al) Mizut. 5. aspecto geral do gametófito. 6. anfigastro. 7. células marginais do filídio. 8. células centrais e trigônios.

Comentários: Ocorre sobre troncos em decomposição reduzida e avançada. Apresenta como características principais: trigônios grandes, espessamentos intermédios ausentes, oleocorpos centrais, 1-2 por célula; lóbulos pequenos, triangulares, dente apical pequeno, obtuso; anfigastros imbricados, 3,0-5,0 vezes a largura do caulídio, orbiculares a reniformes, de inserção profundamente arqueada. Os caulídios são pouco ramificados, longos e flexuosos.

7. Drepanolejeunea mosenii (Steph.) Bischler, Revue Bryol. Lichénol. 35(1-4): 118. 1967.

Descrição e ilustração: Bischler (1967).

Material examinado: BRASIL. Pernambuco: Timbaúba, mata do Engenho Água Azul,17/VII/92, tronco morto, Germano s/n (UFP 8669).

Distribuição no Brasil: ES, MG, PE, PR, RJ, RS, SC, SP.

Comentários: Ocorre sobre troncos em decomposição reduzida. Espécie de pequeno porte, apresentando como características principais: filídios suberetos, assimétricos, lanceolados, ápice longo-acuminado, margem crenulada, ocelos incolores, até $3 \mathrm{em}$ 
fileira descontínua, lóbulos $1 / 3$ a 1/2 do filídio, ocasionalmente reduzidos, com dente longo, curvo, papila hialina proximal; anfigastros pequenos e distanciados.

8. Harpalejeunea tenuicuspis (Spruce) Schiffn. in Engler \& Prantl., Natür. Pflanzenfam. 1(3): 127. 1895.

Descrição: Spruce (1884).

Ilustração: Griffin III (1979).

Material examinado: BRASIL. Pernambuco: Timbaúba, mata do Engenho Água Azul, 17/VII/92, tronco morto, Germano s/n (UFP 8678); 11/IX/92, tronco morto, Germano (UFP 8685).

Distribuição no Brasil: PE, SP.

Comentários: Ocorre sobre troncos em decomposição reduzida. Apresenta como características principais: filídios suberetos, ápice agudo ou acuminado, margem inteira, ocelos incolores 2-3, basais; lóbulos 1/3-1/2 da largura do filídio, nunca reduzidos, dente apical agudo; anfigastros emarginados a ligeiramente bífidos com lobos obtusos e linha de inserção reta.

\section{Harpalejeunea sp.}

Descrição: Gametófitos de porte médio até 1,0mm larg., verde-claros, transparentes; filídios subimbricados, assimétricos, 2-3 dentes no ápice, margem ondulada a crenulada; células arredondadas a hexagonais, de paredes finas, trigônios pequenos, ocelos 2-3 basais; lóbulos fortemente inflados, dente apical unicelular; anfigastros distanciados, bífidos, 1,0-1,5 vezes a largura do caulídio, ápice arredondado. Perianto não observado.

Material examinado: BRASIL. Pernambuco: Timbaúba, mata do Engenho Água Azul, 11/IX/92, tronco morto, Germano s/n (UFP 9245).

Comentários: Ocorre sobre troncos em decomposição reduzida. A amostra foi considerada por Dr. R. Grolle como muito próxima a H. tridens Besch. \& Spruce. Contudo, por ter sido o material bastante reduzido e se encontrar estéril, não foi possível a identificação ao nível específico.

\section{Lejeunea sp.1}

Descrição: Gametófitos de porte médio, ca 1,0mm larg., verde-claros, pálidos, foscos, irregularmente ramificados; ramos flácidos, prostrados; filídios subimbricados, oblíquos-ovalados, ápice abruptamente subagudo, margem inteira a levemente ondulada; células marginais quadráticas $18,5 \mathrm{~mm} \times 16,6 \mathrm{~mm}$, as centrais ovaladas a subalongadas, $23,8 \mathrm{~mm} \times 32,5 \mathrm{~mm}$; trigônios e espessamentos intermédios ocasionais; lóbulos ovalados, inflados, freqüentemente reduzidos; anfigastros distanciados, 1,0- 
1,5 vezes a largura do caulídio, bífidos até quase $1 / 2$ do comprimento, margem inteira. Perianto não observado.

Material examinado: BRASIL. Pernambuco: Timbaúba, mata do Engenho Água Azul, 17/VII/92, tronco morto, Germano s/n (UFP 8686); 11/IX/92, tronco morto, Germano s/n (UFP 9253); 11/IX/92, tronco morto, Pôrto s/n (UFP 9245).

Comentários: Ocorre sobre troncos nas três fases de decomposição. Espécie de morfologia variável, apresentando-se fortemente aderida ao substrato e não portando estrutura reprodutiva. Não foi possível identificar o material estudado ao nível específico, por ser Lejeunea um gênero de delimitação complexa, sendo principalmente as espécies neotropicais numerosas e pobremente conhecidas.

\section{Lejeunea sp. 2}

Descrição: Gametófitos pequenos, ca $0,7 \mathrm{~mm}$ larg., verde-claros, brilhantes, translúcidos; filídios distanciados, ovalados, ápice arredondado, margem inteira a

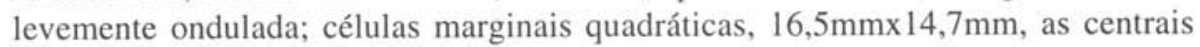
hexagonais, $28,5 \mathrm{~mm} \times 36,7 \mathrm{~mm}$; trigônios pequenos; lóbulos ovalados, inflados, freqüentemente reduzidos; anfigastros distanciados, 1,0-1,5 vezes a largura do caulídio, margem inteira. Perianto não observado.

Material examinado: BRASIL. Pernambuco: Timbaúba, mata do Engenho Água Azul, 11/IX/92, tronco morto, Germano s/n (UFP 9250); 11/IX/92, tronco morto, Pôrto s/n (UFP 9241); 11/IX/92, tronco morto, Germano s/n (UFP 9247).

Comentários: Ocorre sobre troncos nas três fases de decomposição. Espécie próxima a Lejeunea sp. 1, da qual difere, principalmente, pelo tamanho das células e morfologia do filídio. O material examinado apresentava-se fortemente aderido ao substrato e não portava estrutura reprodutiva, não tendo sido possível enquadrá-lo, com segurança, ao nível específico.

12. Prionolejeunea luensis Herzog, Broteria, ser. Cien. Nat. 6(33): 20. 1937.

Descrição e ilustração: Herzog (1937).

Material examinado: BRASIL. Pernambuco: Timbaúba, mata do Engenho Água Azul, 11/IX/92, tronco morto, Pôrto s/n (UFP 8694); 9/II/93, tronco morto, Germano s/n (UFP 8702); 6/V/93, tronco morto, Germano s/n (UFP 8727a).

Distribuição no Brasil: PE, RO.

Comentários: Ocorre sobre troncos nas três fases de decomposição, em pequenas e grandes manchas, geralmente associada a outras briófitas. Apresenta como características principais: os filídios de margem crenulada devido a projeções das células, ocelos ausentes; anfigastros pequenos, bífidos até 1/3-1/2 do comprimento, ocasionalmente com dentes laterais; periantos aplanados, com duas aurículas e lacínias. 
13. Pycnolejeunea contigua (Nees) Grolle, J. Hattori Bot. Lab. 45: 179. 1979.

Descrição: Spruce (1884).

Ilustração: Kachroo \& Schuster (1961) como Pycnolejeunea spruceana Schiffn.

Material examinado: BRASIL. Pernambuco: Timbaúba, mata do Engenho Água Azul, 6/V/93, tronco morto, Germano s/n (UFP 8723).

Distribuição no Brasil: AM, BA, ES, MG, PA, PE, SC, SP.

Comentários: Ocorreu sobre troncos de decomposição reduzida. Apresenta como características principais: filídios imbricados, de margem revoluta quando secos, trigônios e oleocorpos grandes, ocelos 4-8, basais; lóbulos 1/6-1/2 o comprimento do filídio; anfigastros grandes, até 5 vezes a largura do caulídio, orbiculares a reniformes.

14. Rectolejeunea flagelliformis Evans, Bull. Torrey Bot. Club 33: 9. 1906.

Descrição e ilustração: Evans (1906).

Material examinado: BRASIL. Pernambuco: Timbaúba, mata do Engenho Água Azul, 17/VII/92, tronco morto, Germano s/n (UFP 8684b).

Distribuição no Brasil: PE.

Comentários: Ocorre apenas sobre troncos em decomposição reduzida. Apresenta como características principais: gametófitos verde-pálidos, filídios divergentes, planos; trigônios ausentes, oleocorpos às vezes ausentes nas células clorofiladas, ocelos basais, 3-5(6), em série; anfigastros pequenos, linha de inserção quase reta. É comum a reprodução vegetativa por filídios reduzidos e caducos portando rizóides marginais, desenvolvidos em ramos flageliformes.

15. Trachylejeunea crenata (Nees \& Mont.) Schust., J. Hattori Bot. Lab. 72: 253. 1992. (Fig. 9-13)

Descrição: Schuster (1992).

Material examinado: BRASIL. Pernambuco: Timbaúba, mata do Engenho Água Azul, 17/VII/92, tronco morto, Germano s/n (UFP 8679); 11/IX/92, tronco morto, Pôrto s/n (UFP 8747); 9/II/93, tronco morto, Germano s/n (UFP 8707); 6/V/93, tronco morto, Germano s/n (UFP 8727b), det. R. Grolle.

Distribuição no Brasil: PE, como Lejeunea crenata Mont.; AM, SP, como Crossotolejeunea crenata (Nees \& Mont.) Steph. (Yano 1995).

Comentários: Ocorre sobre troncos nas três fases de decomposição. Apresenta como características principais: filídios de margem denticulada, trigônios inconspícuos ou pequenos, espessamentos intermédios raros ou ausentes, ocelos 2-3 basais, lóbulos 
inflados, dente apical agudo, papila hialina proximal. Distingue-se, principalmente, de T. pandurantha (Spruce) Steph. pela ausência de pequenos ocelos adicionais dispersos na parte superior do filídio. A delimitação taxonômica de Trachylejeunea crenata parece complexa ao incluir sinonímias de Crossotolejeunea e Lejeunea, morfologicamente distintos. Sobre o assunto, Schuster (1992) alerta que a inclusão de algumas sinonímias em $T$. crenata pode ser provisória, ficando na dependência de estudos posteriores.

\section{PTYCHANTHOIDEAE}

16. Archilejeunea fuscescens (Hampe ex Lehm.) Fulf., Bryologist 45: 174. 1942.

Descrição e ilustração: Gradstein (1994).

Material examinado: BRASIL. Pernambuco: Timbaúba, mata do Engenho Água Azul, 11/IX/92, tronco morto, Germano s/n (UFP 9249); 9/II/93, tronco morto, Germano s/n (UFP 8719b).

Distribuição no Brasil: AM, PA, PE.
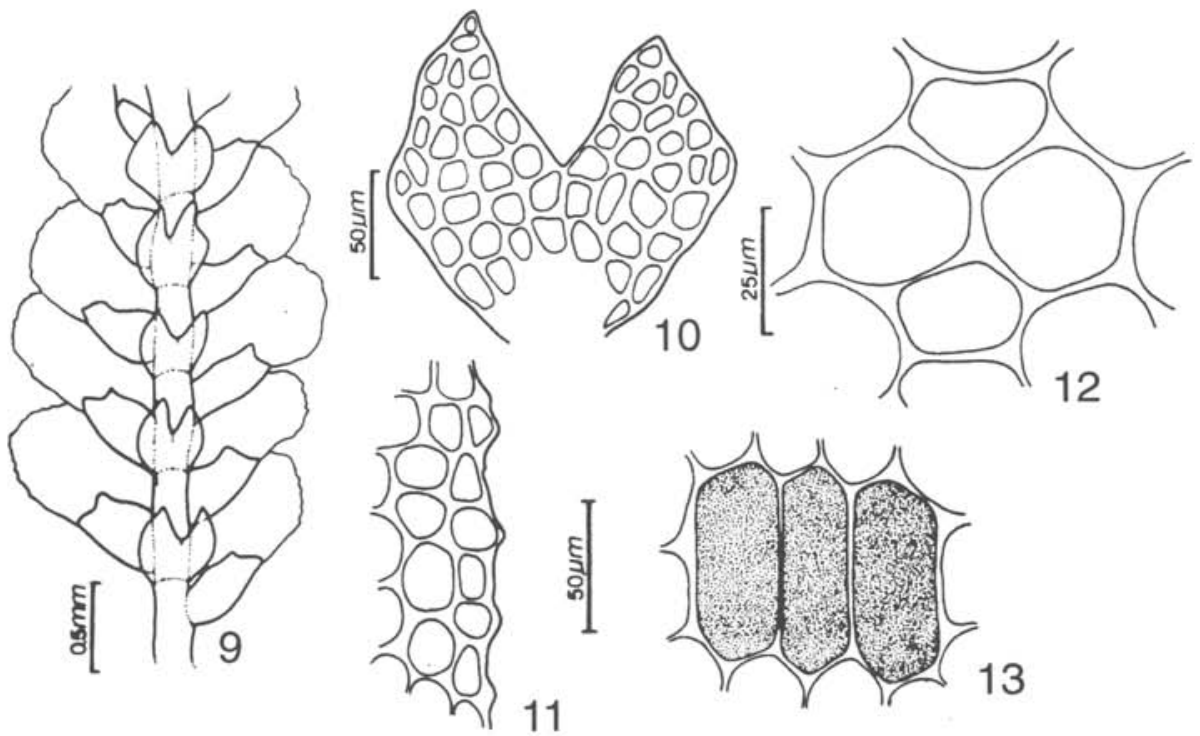

Figuras 9-13. Trachylejeunea crenata (Nees \& Mont.) Schust. 9. aspecto geral do gametófito. 10. células do anfigastro. 11. células marginas do filídio. 12. células centrais do filídio. 13. ocelos basais. 
Comentários: Ocorre sobre troncos em decomposição reduzida e avançada. Apresenta como características principais: parede das células do filídio sem pigmentação escura, oleocorpos 1-2, granulares; lóbulos 1/3-1/2 o comprimento do filídio, retangulares, algumas vezes reduzidos; anfigastros grandes, 3(4-7) vezes a largura do caulídio, linha de inserção reta ou ligeiramente curva; perianto com 4-5 quilhas, lisas ou ligeiramente denteadas.

17. Lopholejeunea subfusca (Nees) Steph., Hedwigia 29: 16. 1890.

Descrição e ilustração: Schuster (1980).

Material examinado: BRASIL. Pernambuco: Timbaúba, mata do Engenho Água Azul, 17/VII/92, tronco morto, Germano s/n (UFP 8686b); 11/IX/92, tronco morto, Pôrto s/n (UFP 8691c); 11/IX/92, tronco morto, Germano s/n (UFP 9259).

Distribuição no Brasil: AC, AM, ES, RR, PE.

Comentários: Ocorre sobre troncos nas três fases de decomposição, usualmente associada a outras Lejeuneaceae. Apresenta como características principais: trigônios grandes, oleocorpos homogêneos; lóbulos 1/4-1/2 o comprimento do filídio, inflados, ovalados, truncados, algumas vezes reduzidos, dente apical $0-1$; anfigastros 2(5-6) vezes a largura do caulídio, linha de inserção reta ou pouco arqueada; perianto com 45 quilhas dentado-laciniadas.

18. Stictolejeunea squamata (Willd. ex Web.) Schiffn., Engler \& Prantl, Natür. Pflanzenfam. 1(3): 131. 1893.

Descrição e ilustração: Gradstein (1994).

Material examinado: BRASIL. Pernambuco: Timbaúba, mata do Engenho Água Azul, 11/IX/92, tronco morto, Pôrto s/n (UFP 8691d).

Distribuição no Brasil: AC, AM, BA, PA, PE, RJ, SP.

Comentários: Ocorre sobre troncos em decomposição intermediária. Apresenta como características principais: ausência de oleocorpos nas células clorofiladas (Gradstein 1994), ocelos numerosos, distribuídos aleatoriamente nos filídios, anfigastros e perianto; filídios e anfigastros com células marginais hialinas e retangulares; lóbulos 1/5-1/4 o comprimento do filídio; anfigastros $3(4-7)$ vezes a largura do caulídio; perianto com 2 quilhas laterais expandidas em aurículas.

19. Symbiezidium barbiflorum (Lindenb. \& Gott.) Evans, Bull. Torrey Bot. Club. 34: 540, pl. 31(11-14). 1908.

Descrição e ilustração: Fulford (1942).

Material examinado: BRASIL. Pernambuco: Timbaúba, mata do Engenho Água Azul, 17/VII/92, tronco morto, Germano s/n (UFP 8671). 
Distribuição no Brasil: AM, ES, PA, PE, RJ, SC, SP.

Comentários: Ocorre sobre troncos em decomposição intermediária. Apresenta como características principais: trigônios grandes, trirradiados, oleocorpos homogêneos, 47 por célula; lóbulos $1 / 5-1 / 4$ vezes o comprimento do filidio, quadrados a retangulares, nunca reduzidos, dente apical 1-2 células; anfigastros 3(4-8) vezes a largura do caulidio, linha de inserção profundamente arqueada; face ventral do perianto com cilios ou lacinias, distribuidas em 1-2 fileiras.

\section{Agradecimentos}

Os autores agradecem pela gentil colaboração na identificação de algumas espécies, ao Dr. Riclef Grolle, do Herbarium Haussknecht, Friedrich-Schiller Universität, Jena, Alemanha.

\section{Referências bibliográficas}

Baptista, M.L.L. 1977. Flora llustrada do Rio Grande do Sul: Lejeuneaceae. Boletim do Instituto Central de Biociências 36: 1-139.

Bischler, H. 1967. Le genre Drepanolejeunea Steph. en Amérique Centrale et Méridionale. Revue Bryologique et Lichénologique 35(1-4): 95-134.

Evans, A.W. 1906. Hepaticae of Puerto Rico - VI Cheilolejeunea, Rectolejeunea, Cystolejeunea and Pycnolejeunea. Bulletin of the Torrey Botanical Club 33:1-25.

Evans, A.W. 1911. Hepaticae de Puerto Rico X. Cololejeunea, Leptocolea and Aphanolejeunea. Bulletin of the Torrey Botanical Club 38: 368-403.

Fulford, M. 1942. Studies on American Hepaticae IV. A revision of genus Symbiezidium. Lloydia 5(4): $293-$ 304.

Fulford, M. 1945. Studies on American Hepaticae. VI. Ceratolejeunea. Brittonia 5(4): 368-403.

Germano, S.R. \& Pôrto, K.C. 1996. Floristic survey of epixylic Bryophytes of an area remnant of the Atlantic Forest (Timbaúba-PE, Brazil). I. Hepaticopsida (except Lejeuneaceae) and Bryopsida. Tropical Bryology 12: $21-28$.

Germano, S.R \& Pôrto, K.C. 1997. Ecological analysis of epixylic bryophytes in relation to the decomposition of the substrate (Municipality of Timbaúba - Pernambuco, Brazil). Cryptogamie, Bryologie-Lichénologie 18(2): $143-150$.

Giancotti, C. \& Vital, D.M. 1989. Flora briofitica da Reserva Biológica do Alto da Serra de Paranapiacaba, São Paulo: 1-Lejeuneaceae (Hepaticopsida). Acta Botanica Brasilica 3(2): 169-177.

Gradstein, S.R. 1994. Lejeuneaceae. Ptychantheae, Brachiolejeuneae. Flora Neotropica. Monograph 62. The New York Botanical Garden, 1-215p.

Griffin III, D. 1979. Guia preliminar para as briófitas freqüentes em Manaus e adjacências. Acta Amazonica 9(3): 1-67.

Herzog,T. 1937. Neue Hepaticae aus Sudamerika. Broteria 6(1): 7-23.

Kachroo, P. \& Schuster, R.M. 1961. The Genus Pycnolejeunea and its affinities to Cheilolejeunea, Siphonolejeunea and Strepsilejeunea. Journal of the Linnean Society, Botany 56: 475-511.

Mizutani, M. 1982. Notes on the Lejeuneaceac. 6. Japanese species of the genus Cheilolejeunea. Journal of the Hattori Botanical Laboratory 51:151-173.

Pócs, T. 1982. The Tropical Bryophytes. Pp. 54-104. In A.J.E. Smith (Ed.), Bryophyte Ecology. Chapman and Hall, London.

Pôrto, K.C. 1990. Bryoflores d'une fôret de plaine et d'une fôret d'altitude moyenne dans l'état de Pernambuco (Brésil): Analyse floristique. Cryptogamie, Bryologie-Lichénologie 11: 19-161.

Pôrto, K.C. 1992. Bryoflores d'une fôret de plaine et d'une fôret d'altitude moyenne dans l'état de Pernambuco (Brésil) 2. Analyse écologique comparative des forêts. Cryptogamie, Bryologie-Lichénologie 13:187219. 
Richards, P.W. 1984. The ecology of tropical forest bryophytes. Pp. 1233-1970. In: R. M. Schuster (Ed.), New Manual Bryology, v.2.

Schäfer-Verwimp, A. \& Vital, D.M. 1989. New or interesting records of Brazilian bryophytes. Il. Journal of the Hattori Botanical Laboratory 67: 313-321.

Schäfer-Verwimp, A. 1991. Contribution to the knowledge of the Bryophyte flora of Espirito Santo, Brazil. Journal of the Hattori Botanical Laboratory 69: 47-170.

Schuster, R.M.1980. The Hepaticae and Anthocerotae of North America IV. Columbia University Press. 1334p, New York.

Schuster, R.M. 1992. The oil-bodies of the Hepaticae. II. Lejeuneaceae. Journal of the Hattori Botanical Laboratory 72: 253.

Söderström, L. 1987. Dispersal as a limiting factor for distribution, among epixylic bryophytes. Symposia Biologica Hungarica 35: 465-483.

Spruce, R. 1884. Hepaticae Amazonicae and Andinae. Transactions and Proceedings of the Botanical Society of Edinburgh 15:1-308.

Vital, D.M.; Giancotti, C. \& Pursell, R.A. 1991. The Bryoflora of Fernando de Noronha, Brazil. Tropical Bryology 4: 23-24.

Vital, D.M. \& Visnadi, S.R. 1994. Bryophytes of Rio Branco Municipality, Acre, Brazil. Tropical Bryology 9: 69-74.

Yano, O. 1984a. Briófitas. In: O. Fidalgo \& V.L.R. Bononi (Coord.), Técnicas de coletas, preservação e herborização de material. Instituto de Botânica, São Paulo.

Yano, O. 1984b. A checklist of Brazilian liverworts and hornworts. Journal of the Hattori Botanical Laboratory 56: $481-548$.

Yano, O, 1989. Ap additional checklist of Brazilian Bryophyte. Journal of the Hattori Botanical Laboratory 66: $371-434$.

Yano, O. 1995. A new additional annotated checklist of Brazilian Bryophytes. Journal of the Hattori Botanical Laboratory 78: 137-182.

Yano, O. \& Lisboa, R.C. 1988. Briófitas do Território Federal do Amapá, Brasil. Boletim Museu Paraense Emilio Goeldi, série Botânica 4(2): 243-270.

Yano, O. \& Mello, Z.R. 1992. Briófitas novas para o Estado de Roraima, Brasil. Acta Amazonica 22(1): 2350. 